\title{
Study on Feasibility of MBO in College Management
}

\author{
Xihuai Liu \\ Department of Economics and Management \\ Zhoukou Normal University \\ Zhoukou 466001, China \\ E-mail: huaixi06@163.com
}

\begin{abstract}
At first, MBO was widely applied in management of enterprises. This paper organically makes some characteristics of MBO and college management together to talk about the feasibility of MBO in college management.
\end{abstract}

Keywords: MBO (management by objectives), College management, Intellectual employee, Feasibility

\section{Introduction}

MBO (Management by objectives) was firstly put forward by peter F. Drucker (who was a well-known scholar of management in America) in 1954. MBO was applied in many organizations after a number of management scholars developed and perfected it. $\mathrm{MBO}$ is a comprehensive and democratic systemic management style which is work-centered and people-centered. $\mathrm{MBO}$ is a suit of systematization democratic management style which Higher-level and lower-level managers and employees in a organization together set down the common organization goal, form one goal system and specify and outspread to every department, every administrative level, every employee in organization and ties nearly up with their duty and production of every department, every administrative level, every employee within organization, definitely prescribe their consecration and encouragement.

MBO is different from traditional goal. conventional goals are made by the top management then decompose them into all levels of organization, which is one kind of unilateralism process superior make give goals to junior. Such goals are non-operational because junior just passively accept goals. Managers of all levels explain these goals with a lot of understanding of their own even with prejudice because of the lack of communication. As a result, goals will lose those clarity and consistency during the process of decomposition from above to below, even passive embracer of goals often complain. They consider goals are non-reasonable, their work enthusiasm decline and so on, which directly result in lacking power of implementation. The core of MBO is made goals by top and lower levels of organization together and form goals system, so that the specific objectives of the organization become action direction and motivation of each member, each level, each department, at the same time these goals become standards which check work performance of each member, each level, each department, thus the organization can effectively run. MBO emphasizes self-directing, self-control, not by his superiors to command and control.

\section{Bring forward the problem}

In general, Institutions of higher learning are places which intellectual employees are dense. So-called intellectual employees mean them have their own strong power of learning knowledge and innovating knowledge and innovate, spread, share, use knowledge in the organization and create greater value for the organization. How to motivate knowledge workers, in recent years, many scholars from home and abroad carry through theory exploring and demonstration analysis from incentive factors and so on. However, existing studies are often concerned about infection intension of all kinds of incentive factors namely environmental force on action individual---incentive external force. However, self -motivation about action individual ---incentive internal force is not attracted sufficient attention. Could MBO apply in universities management to effectively motive these knowledge-based employees? This paper organically made some characteristics of $\mathrm{MBO}$ and college management together to talk about the feasibility of MBO in college management.

\section{Feasibility analysis of $\mathrm{MBO}$ in the management of colleges and universities}

\subsection{MBO in college management easily forms motivation function.}

The goal is the expected results which one organization achieves through efforts during a certain period in the future. Motivation means improving employee's work enthusiasm and guiding their action in organization management by influencing realization of individual need of employees. The purpose of motivation is to encourage members to mobilize the enthusiasm of the work and to stimulate their initiative and creativity in order to improve the organization 
efficiency. Goal has a strong incentive function for their employees. When the goal becomes a sort of result which every level, every department and every member of the organization wish to accept in the future, and the possibility of realization is quite great, the goal becomes internal incentives of members of the organization. Especially when realize the result and the organization has corresponding reward, incentive function of goal will be more great. With regard to goal turning into incentive factors this kind of had better is the goal which every level, every department and every member of the organization to make themselves.MBO just reflect this side.

\subsection{MBO in college management easily forms agglomerate function.}

Every department, every member of the organization together design common goal and form one goal system, and has their own sub-goal, the organization has its common goal. In order to realize common goal, everybody must unite as one and work together to achieve their individual goal to achieve the common goal of the organization. As regard as colleges and universities which knowledge-based staff are dense, MBO will help every faculty to agglomerate as one to put their shoulder to the wheel to realize the common goal of colleges and universities, which not only realize the common goal of school but also every faculty realizes their own goals and gains corresponding encouragement and rewards.

\subsection{MBO in college management has check function.}

MBO provides manager with one standard which can effective check and evaluate employees, of course, MBO also one kind of effective evaluation tool for managers. Present examination for faculty in some colleges are just the same traditional conventionality which the result of examination are short of credibility and mostly are superior to subordinate, leaders to underlings, function departments to teaching departments. However, MBO designs goals for every department with different levels and various employees and regard these goals as the standard which evaluates their work performance and rewards. Therefore, MBO provides college management with one viable means.

\subsection{MBO provides college management with one effective democratic management means.}

First of all, MBO is one democratic management style, because everybody together designs their common goal, rather than the superiors design the goal then distribute it to juniors. This kind of democratic management way not only improves faculty's enthusiasm, initiative and creativity but also satisfies the mental needs of lots of faculty participating in management. In addition, MBO surely can improve efficiency of organization management. The means of MBO are better than the means of plan management regarding as promoting college management and realizing the ultimate goal. Because MBO is not only activities work of plan, but also a management style of result. This management style forces every level, every department and every member of the organization to firstly consider realizing goals which are decomposition of the organization's overall goal. Therefore, when goals of every level, every department and every Members of the organization are achieved, the overall goal of the organization is also achieved. Once decomposition goals conformed and not conform means or ways which every level, every department and every Members of the organization achieve their own goals, which provide everyone with one innovative room for achieving goals, which effectively improve Organization's management efficiency.

\subsection{MBO in college management will help to clear its own task.}

MBO can help all levels directors and members of the organization to clearly know the overall goal, structure system, division and cooperation of the organization and their own tasks. This responsibility makes executives to understand that they should given the power to lower levels rather than a monopoly of power in order to complete the goals.

\subsection{MBO provides college management with one style of self-control, self-management.}

With regard to colleges and universities which knowledge-based staff are dense, some faculty do not want to work under the control of the others after they clearly know their own tasks and goals, but complete their own tasks and goals of work with the style of self-management, self-control. MBO is actually one self-management, self-controlled manner, or is one style which guides every member of the organization to self-management, self-control. In the implementation of MBO every member of the organization not only do work, implement instructions, wait for guidance and decision -making, but also every member already unit or individual whom have definitude goals. On the one hand, members of the organization have participated in working-out of goals and gained the organization's approbation; On the other hand, how to realize their tasks is their own things during members of the organization realize their own goals once goals already made. In this sense, MBO can be at least one style of self-management, self-control.

\subsection{MBO provides college management with one effective control means.}

Control is one important management function, so-called control is one process which supervise, examine that the work whether is taken according to established plans, standards and methods, then find the deviation and analyze the reasons and correct the deviation in order to ensure to realize the goals of the organization. We must have the control to realize the established goals of the organization.MBO itself is one effective control means, that is, through the realization of decomposed goals, the process which finally ensure that achieve the overall goals of the organization is means of result 
control.MBO is not simple decomposition of goals, in fact, high-level directors of the organization must often examine, compare goals and appraise, and correct the deviation if they appear. From another point of view, if an organization has a clear assessable target system, the target system itself is the best gist of intendance control.

\subsection{MBO in college management incarnates people-oriented management philosophy.}

So-called people-oriented management refers a sort of management means which regard the people's all-round development as the core, create corresponding environment, conditions, and is on base of individual self-management, self-control, which is based on the basic assumptions about people, that is, regarding human as society people whom pursue self-realization, self-management, self-control. Some scholars put forward to carry out people-oriented management in the management of colleges and universities, that is, put forward "three the whole shoot", which is the work of all levels leaders in colleges and universities, all for all faculty and students, for all of all faculty and students, for all faculty and students. MBO is justly a people-centered, democratic management style which emphasizes self-control, self-realization, self-management. Therefore, MBO in the management of colleges and universities can preferably reflect the people-centered administration ideas and philosophy.

\subsection{MBO in college management can satisfy lots of faculty mental needs of self-realization.}

American psychologist A. Maslow wrote the book "The motive theory on human" in the 1943, in which he put forward the theory of the five needs levels, there was one tiptop need----self-realization need. self-realization is to exert oneself to promote self-growth, try one's best to exert own potential and realize own value, do one's best to realize maximal achievement, which is the highest demand level. In addition, self-realization is also a theory of human nature hypothesis, namely, human hypothesis of self-realization. MBO is a style of self-management which is just on base of the human hypothesis of self-control, self-realization. Therefore, MBO provides faculty in colleges and universities with a platform of self-realization.

\section{Conclusion}

MBO was initially applied in the operation and management of enterprises, Chinese enterprises introduced the method of MBO in the 1980s, which has achieved good results. However, MBO in the management of colleges and universities has not been attached importance to. Can use MBO to mobilize everybody's enthusiasm, initiative and creativity for knowledge-intensive colleges and universities? According to analysis and discussion above, the authors think that: MBO in the management of colleges and universities is totally feasible. But how to use it, and what should be paid attention to,the author will do further study and research.

\section{References}

Guo-Hua Xu, De Zhang \& Ping Zhao. (1998). Management, Beijing: Tsinghua University Press.

Ming-Jie Rui. (2005). Management - a modern point of view, Shanghai: Shanghai People's Publishing House.

Patrick. J. Montana \& Bruce. (2004). H. Vladimir Richard. Management, Shanghai: Shanghai People's Publishing House.

San-Duo Zhou Chuan-ming, Chen. (2005). Management - Principles and Methods, Shanghai: Fudan University Press.

Stephen. P. Robbins. (1997). Organizational behavior, Beijing: China People's University Press. 